\title{
Intranodal Lymphangiography and Lymphatic Embolization Treatment for Groin Lymphorrhea: A Preliminary Vietnamese Report
}

\author{
Nguyen Ngoc Cuong (D) \\ Pham Hong Canh' \\ Le Tuan Linh ${ }^{1,2}$ \\ Nguyen Minh Duc $\mathbb{1}^{2-4}$ \\ Thieu Thi Tra My ${ }^{1,2}$ \\ Le Hoan (D) ${ }^{5}$ \\ 'Diagnostic Imaging and Interventional \\ Radiology Center, Hanoi Medical \\ University Hospital, Ha Noi, Vietnam; \\ ${ }^{2}$ Department of Radiology, Hanoi Medical \\ University, Ha Noi, Vietnam; \\ ${ }^{3}$ Department of Radiology, Pham Ngoc \\ Thach University of Medicine, Ho Chi \\ Minh City, Vietnam; ${ }^{4}$ Department of \\ Radiology, Children's Hospital 2, Ho Chi \\ Minh City, Vietnam; ${ }^{5}$ Respiratory \\ Medicine Department, Hanoi Medical \\ University Hospital, Hanoi, Vietnam
}

Correspondence: Le Hoan

Respiratory Medicine Department, Hanoi Medical University Hospital, Hanoi,

Vietnam

Tel +84372286666

Email lehoan.hmu@gmail.com
Purpose: This article described intranodal lymphangiography and embolization of patients with lymphatic leak post-operation of the groin region for various aetiologies (lymph node resection, femoral artery exposure).

Materials and Methods: A retrospective analysis from 2018 to 2020 was performed and twelve consecutive patients underwent intranodal lymphangiography and intranodal lymphatic embolization to treat lymphorrhea or lymphocele post-operation of the groin. All the lymph nodes around the wound were punctured for lymphangiography. If the extravasation was found from the lymph node, the glue N-butyl cyanoacrylate (NBCA) diluted with lipiodol (ratio of 1:4) was injected to occlude the lymphatic vessel laceration.

Results: All the lymph nodes around the wound were punctured with the median number of two lymph nodes for each patient (range from one to four lymph nodes); there were three patients with two leakage points. Intranodal lymphatic embolization was performed by glue NBCA diluted 1:4 with lipiodol. Additional treatment includes sclerotherapy $(n=5)$ and percutaneous muscular flap operation $(n=1)$. Clinical successful was achieved in twelve patients $(100 \%)$ with no major complications. One patient experienced lymphedema which was was treated by compression stockings and rehabilitation therapy.

Conclusion: Intranodal lymphangiography and embolization are effective methods to treat iatrogenic lymphatic leak while all the lymph nodes around the wound should be punctured to avoid missing lesions from other lymphatic vessels.

Keywords: intranodal lymphangiography, intranodal lymphatic embolization, groin lymphatic leak, lymphorrhea

\section{Introduction}

Groin lymphorrhea or lymphocele complications following operation of groin region is common. ${ }^{1,2}$ It happens in $11 \%$ patients who have undergone a femoropopliteal bypass graft operation and about $5 \%$ of patients with femoral exposure for aortic endovascular intervention. ${ }^{3}$ Most post-operative lymphorrhea can stop spontaneously after several weeks of conservative treatment. In some cases, with a high flow of lymphatic leak, treatment will be complicated requiring repeated operations, or even amputation. ${ }^{3}$ Intranodal lymphangiography and glue embolization might be an effective treatment in these patients as it helps to reduce the time of wound healing. The technical and clinical success rate of this technique was up to $100 \%$ and $80 \%$, respectively. ${ }^{2}$ Little is known about the anatomy of the lymphatic vessels that connect the lymph nodes at the groin. It is supposed that there are many 
interconnecting lymphatic vessels between the lymph nodes with different directions. ${ }^{4}$ Thus, lymph node resection or incision can damage several lymphatic vessels toward the different corresponding lymph node, causing leakage. In this article, we purposed to evaluate the safety and effectiveness of intranodal lymphangiography and embolization of patients with lymphatic leak for postoperative lymphatic leakage.

\section{Methods}

\section{Patients' Population}

This retrospective study was approved by the local ethical institute board without obtaining informed consent. All patients had post-surgery lymphatic leakage of the groin region and failure of conservative or operative treatment were included into our study. Groin lymphatic leak manifested as lymphocele or lymphorrhea from the wound with the volume of fluid drain was more than $100 \mathrm{~mL}$ per 24 hours. All patients were undergone intranodal lymphangiography and intranodal embolization by glue. Images and medical records were collected at the Department of Radiology of the Ha Noi Medical University Hospital (Ha Noi, Viet Nam) from twelve patients from 2018 to 2020. Twelve patients (seven men; five women) with the mean age of 67 , presented with lymphatic leak post-operation as described in Table 1.

\section{Intranodal Lymphangiography Technique}

The intranodal lymphangiography technique was wellknown and described in the literature. ${ }^{5}$ We first punctured the lymph nodes just under the leakage point under ultrasound guidance using the 25-gauge-needle. Oiled contrast agent was slowly injected into the lymph node (Lipiodol, Guerbet, France). If there was extravasation of contrast into the open wound or lymphocele, the diluted glue (NButyl cyanoacrylate [NBCA] mixed with lipiodol ratio $1: 4)$ was then injected into the lymph node using the previous lymphangiography needle. Embolization of the lymph node stopped until there was extravasation of glue. The other lymph nodes around the wound were punctured for lymphangiography to confirm that no leakage point was seen from other lymph nodes. Technical success was defined when all the lymph nodes and the afferent lymphatic vessels into the wound were filled with glue. Medical record was then documented to obtain the volume of the lymphatic leak and to obtain the additional treatments.

\section{Clinical Data}

Inguinal lymphatic leak aetiologies, type of lymphatic leak include lymphorrhea and lymphocele, treatment before intranodal lymphangiography, the number of lymph node punctured for lymphangiography, the number of leakage point, additional treatment after intervention, the time of the resolution, and complications were obtained.

\section{Statistical Analysis}

Our data include the clinical characteristics of patients with lymphatic leak post-operation of the groin region treated with intranodal lymphangiography and embolization. The variables are displayed as numbers, median, and mean.

\section{Results}

Inguinal lymphatic leak aetiologies include lymph node resection $(n=7)$ and femoral artery exposure for catheterization $(n=5)$. There were seven patients with lymphorrhea and five patients with lymphocele who needed to be drained. Six of twelve patients underwent operation suture the lymphatic vessels at least one time; six patients were sent directly to intervention after failed conservative treatment. The median number of lymph nodes punctured for lymphangiography in each patient was two (range from one to four). Lymphangiography showed extravasation of contrast in twelve patients in which three patients had more than one leakage point (Figures 1-3). One of the twelve patients needed to have two sessions of lymphangiography and intranodal embolization. The average volume of NBCA diluted 1:4 with lipiodol was $1.5 \mathrm{~mL}$ for each lymph node. Five patients whose fluid drain volume remained about $50 \mathrm{~mL}$ per day despite significant reduction needed additional treatment with sclerotherapy using absolute ethanol. One patient was indicated for percutaneous muscular flap operation because of the large wound after repeated operations for ligation of lymphatic vessels previously. The average time of the resolution was ten days (range, 1-25 days). One patient had mildly lymphedema of the ipsilateral leg that was then reduce by compress stocking and rehabilitation treatment.

\section{Discussion}

The lymphatic system from the heel region converge to the popliteal node and ascend along the deep femoral artery, while the superficial lymphatic system in the lower extremities the toes and soles of the feet toward the 


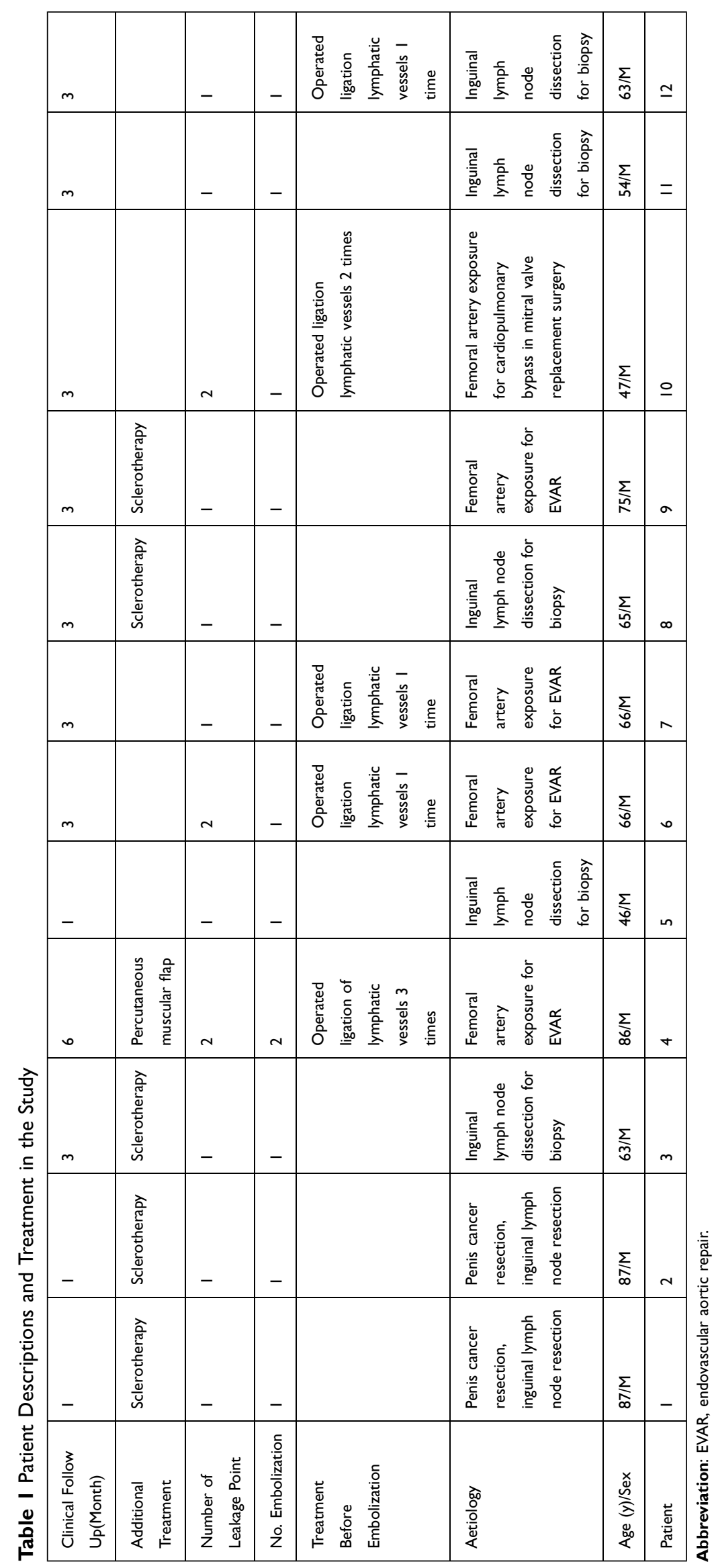




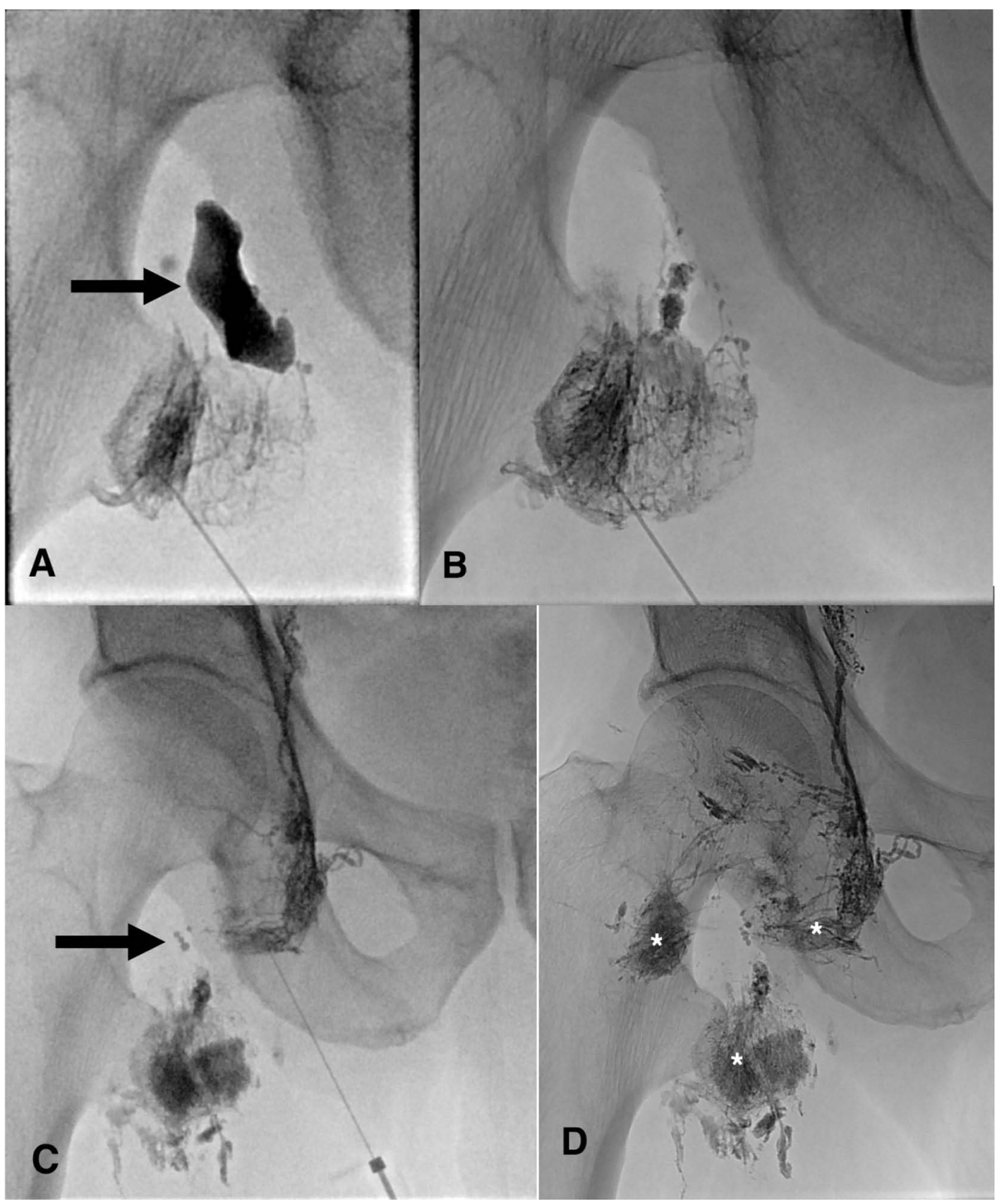

Figure I Patient 4. (A) intranodal lymphangiography show extravasation of contrast into the wound (arrow). (B) after embolization of the lymph node. (C) there was also extravasation from another lymph node during the second session of lymphangiography (arrow). (D) A total of three lymph nodes around the wound were punctured for lymphangiography (stars). Two of the three lymph nodes were embolized by NBCA.

anteromedial thigh and connect to two or three dominant lymph nodes at the bottom of the femoral triangle. ${ }^{4}$ This explains why an incision of the groin may damage many lymphatic vessels. Obara et $\mathrm{al}^{3}$ reported that the incidence rate of lymphatic complications after femoral artery interventions was as high as $18 \%$. The incidence of lymphatic complications after inguinal lymph node dissection was reported up to $64 \% .{ }^{6,7}$ Inguinal high flow lymphatic leak post-operation often has a longhealing time and may cause severe complications. ${ }^{8}$

The management of lymphoceles and lymphorrhea includes observation, compression therapy, percutaneous drainage, chemical sclerotherapy, surgery, and lymphatic embolization. ${ }^{3,9}$ Intranodal lymphangiography and intranodal lymphatic embolization is an effective treatment as an alternative to open surgery for lymphatic ligation. ${ }^{2}$ It 

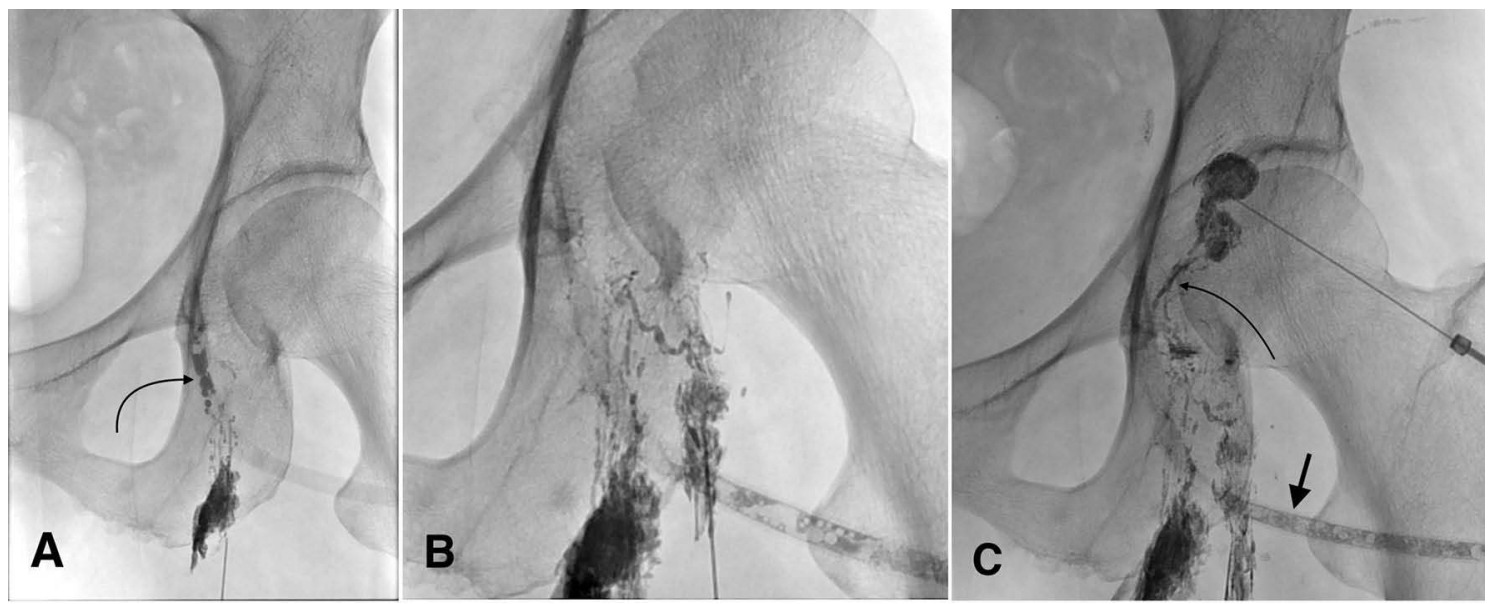

Figure 2 Patient 6. (A) leakage point (arrow) was shown from the lymph node inferior to the wound. (B) The second lymph node showed no extravasation. (C) An extravasation from the lymphatic branch (curved arrow) that comes from a lymph node situated superior to the wound. Contrast was aspirated into the drain (straight arrow).

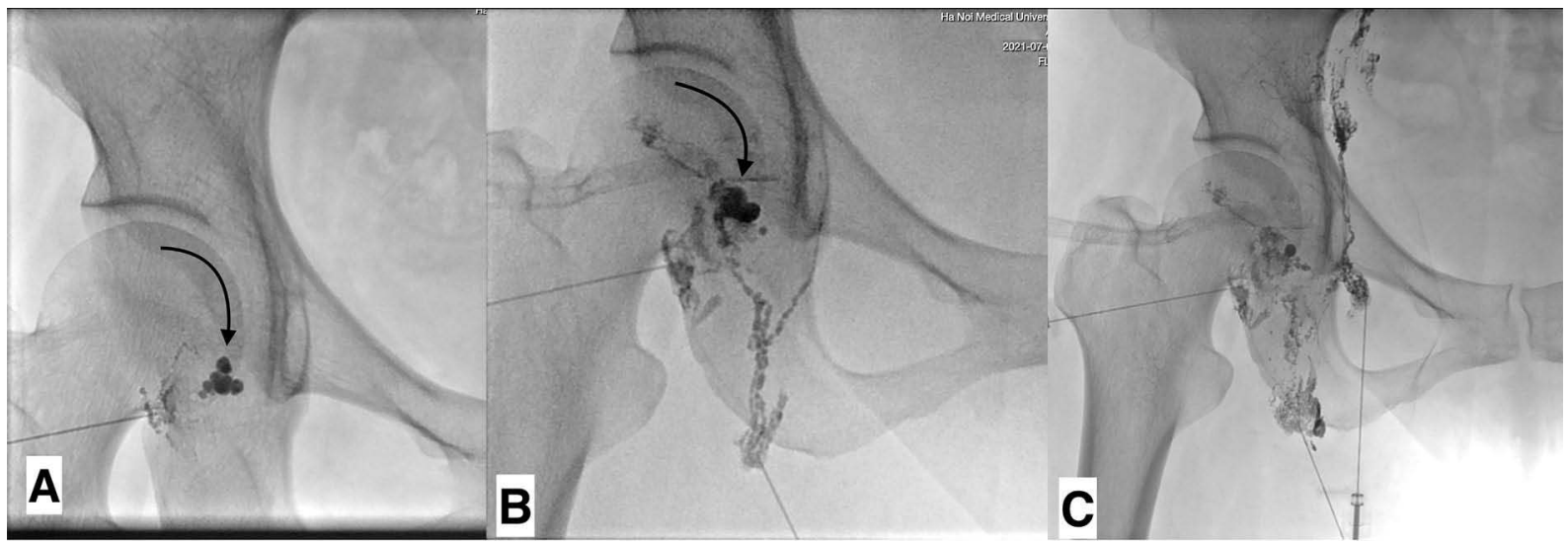

Figure 3 Patient 10. (A) An extravasation from the lymph node (arrow) just under the wound. (B) another extravasation from the lower part of the wound (arrow). (C) A total three lymph nodes were punctured in which two branches showed laceration leakage.

reduces the time of resolution. There were a few studies about Intranodal embolization for the management of groin lymphocele and lymphorrhea, most of them are sporadic reports or based on a small sample. . $^{210,11}$

Chick et $\mathrm{al}^{10}$ reported the first case of successful endolymphatic embolization with NBCA treatment of inguinal lymphocele after femoral bypass graft surgery. The study of Smolock et $\mathrm{al}^{2}$ included ten patients with inguinal lymphatic leaks due to femoral vessel catheterization and urogynecology surgery who underwent intranodal lymphangiography and embolization. The authors also use $\mathrm{NBCA}$ as in this study, some patients underwent more than one treatment of lymphatic embolizations or lymphocele sclerotherapy. Two in ten patients who failed embolization received additional treatments include laparoscopic repair, lymphatic ligation, and flap closure. The median time to resolution was seven days while in our study was ten days. Tanahashi et $\mathrm{al}^{11}$ treated lymphorrhea in the groin after surgery of anal cancer by puncture directly into leakage points under fluoroscopy. A recent study of Moussa et $\mathrm{al}^{12}$ regarding management of pelvic and retroperitoneal lymphoceles demonstrated that lymphangiogram and lymphatic embolization were safe and effective methods for the management of lymphoceles.

In our study, patients often underwent surgery before being referred to our hospital. It led to being more completed to treat and needed a long time for the wound to heal. A ligated operation may enlarge the wound and damage more than one lymph node. There were three patients with more than one leakage point, so, the lymphangiography of the other groin lymph nodes must be required to determine the other leak points. There were six patients received additional treatments 
in which five patients received sclerotherapy and one patient had a percutaneous muscular flap operation. Additional treatments were required in patients with lymphatic leak which did not resolved completely after embolization. In term of technical aspects and outcomes, our experiences showed that there was no difference between cancer or non-cancer cases. Therefore, we recommended all the inguinal lymph nodes should be performed by lymphangiography.

Intranodal embolization for inguinal lymphatic leaks is safe and effective with a high success rate. Some advantages of this technique are that it is minimally invasive, has short procedural times and prompt clinical results, and would apply even after the failure of surgery. Potential risks of the procedure such as leg edema have been reported. ${ }^{2}$ Severe lymphedema is an incurable complication of this procedure, therefore, we recommend that not all inguinal lymph nodes are embolized. The early signs of lymphedema should be detected so that indication treatment is started promptly using compression stockings and physiotherapeutic rehabilitation.

Our study had several limitations. Firstly, the sample size was limited, because intranodal lymphangiography and embolization of the groin lymphorrhea is a new technique. Secondly, long-term follow-up is necessary to assess the durability of results. Moreover, operation suture the lymphatic vessels before intranodal embolization may affect the clinical results of this technique. In future, other studies with larger sample sizes can more objectively assess the effectiveness and safety of this technique.

\section{Conclusion}

This study showed that intranodal lymphatic embolization is a potential approach of choice for groin lymphatic leaks after groin region operation. This procedure appeared to be safe, with a high success rate.

\section{Ethical Approval}

All procedures performed in studies involving human participants were in accordance with the ethical standards of the institutional and/or national research committee and with the 1964 Helsinki declaration and its later amendments or comparable ethical standards. This study was approved by the local ethics committee of Hanoi medical university hospital.

\section{Informed Consent}

Patients' informed consent included in this research was obtained from all individual participants in the study.

\section{Consent for Publication}

Consent for publication was obtained for every individual person's data included in the study.

\section{Funding}

This study was not supported by any funding.

\section{Disclosure}

All authors declare that they have no conflicts of interest for this work.

\section{References}

1. Gerken ALH, Herrle F, Jakob J, et al. Definition and severity grading of postoperative lymphatic leakage following inguinal lymph node dissection. Langenbecks Arch Surg. 2020;405(5):697-704. doi:10.1007/s00423-020-01927-7

2. Smolock AR, Nadolski G, Itkin M. Intranodal glue embolization for the management of postsurgical groin lymphocele and lymphorrhea. $J$ Vasc Interv Radiol. 2018;29(10):1462-1465. doi:10.1016/j.jvir.2018.04.020

3. Obara A, Dziekiewicz MA, Maruszynski M, Witkowski A, Dąbrowski M, Chmielak Z. Lymphatic complications after vascular interventions. Videosurgery Miniinvasive Tech. 2014;3:420-426. doi:10.5114/wiitm.2014.43021

4. Suami H, Scaglioni M. Anatomy of the lymphatic system and the lymphosome concept with reference to lymphedema. Semin Plast Surg. 2018;32(01):005-011. doi:10.1055/s-0038-1635118

5. Nadolski GJ, Itkin M. Feasibility of ultrasound-guided intranodal lymphangiogram for thoracic duct embolization. $J$ Vasc Interv Radiol. 2012;23(5):613-616. doi:10.1016/j.jvir.2012.01.078

6. Chang SB, Askew RL, Xing Y, et al. Prospective assessment of postoperative complications and associated costs following inguinal lymph node dissection (ILND) in melanoma patients. Ann Surg Oncol. 2010;17(10):2764-2772. doi:10.1245/s10434-010-1026-z

7. de Vries M, Vonkeman WG, van Ginkel RJ, Hoekstra HJ. Morbidity after inguinal sentinel lymph node biopsy and completion lymph node dissection in patients with cutaneous melanoma. Eur J Surg Oncol. 2006;32(7):785-789. doi:10.1016/j.ejso.2006.05.003

8. Kortes N, Radeleff B, Sommer CM, et al. Therapeutic lymphangiography and CT-guided sclerotherapy for the treatment of refractory lymphatic leakage. J Vasc Interv Radiol. 2014;25(1):127-132. doi:10.1016/j.jvir.2013.10.011

9. Karcaaltincaba M, Akhan O. Radiologic imaging and percutaneous treatment of pelvic lymphocele. Eur J Radiol. 2005;55(3):340-354. doi:10.1016/j.ejrad.2005.03.007

10. Chick JFB, Reddy SN, Nadolski GJ, Dori Y, Itkin M. Single-session endolymphatic glue embolization of lymphocele after heart transplantation. J Vasc Interv Radiol. 2016;27(6):929-930. doi:10.1016/j. jvir.2016.02.023

11. Tanahashi Y, Kawada H, Goshima S, Takahashi T, Yoshida K, Matsuo M. Intranodal popliteal lymphangiography for postoperative lymphorrhea after inguinal node dissection. $J$ Vasc Interv Radiol. 2020;31(11):1926-1929. doi:10.1016/j.jvir.2020.03.018

12. Moussa AM, Camacho JC, Maybody M, et al. Percutaneous lymphatic embolization as primary management of pelvic and retroperitoneal iatrogenic lymphoceles. J Vasc Interv Radiol. 2021. doi:10.1016/j. jvir.2021.07.022 


\section{Publish your work in this journal}

Reports in Medical Imaging is an international, peer-reviewed, open access journal publishing original research, reports, reviews and commentaries on all areas of medical imaging. The manuscript management

system is completely online and includes a very quick and fair peerreview system, which is all easy to use. Visit http://www.dovepress. com/testimonials.php to read real quotes from published authors.

Submit your manuscript here: https://www.dovepress.com/reports-in-medical-imaging-journal 